\title{
Produtividade e Mão-de-Obra na Indústria Siderúrgica Brasileira
}

Heinrich Rattner*

Sumário:1. Introdução. 2. Siderurgia: Indústria Basica. 3. O Planejamento dos Recursos Humanos. 4. Caracterização das Emprêsas Estudadas. 5. A Mão-de-Obra nas Oito Emprêsas Siderúrgicas. 6. Conclusões. 7. Considerações Finais.

\section{Introdução}

Medir a produtividade significa avaliar a eficiência e a racionalidade das atividades econômicas. No nível das emprêsas, essa medida é definida como a relação entre o output/input ou valor de produção/insumo. Elevar o nível de produtividade significa aumentar o valor de produção (output), com a mesma combinação dos fatôres de produção (input), ou ainda, manter o nível de produção, realizando economias no insumo dos fatôres. Os índices assim obtidos - Valor de Produção ou Volume de Produção/Número de Empregados - permitem uma verificação do estado de saúde econômica da emprêsa, bem como a comparação dos relativos índices, entre as diferentes emprêsas do mesmo setor industrial.

Muitas vêzes, por motivos nem sempre justificados, as próprias emprêsas dificultam $o$ acesso às informações estatísticas $e$, assim, a realização de estudos comparativos entre elas. Entretanto, o aumento da produtividade, ou sua estagnação, e a análise de suas causas constituem instrumentos dos mais valiosos no planejamento e na execução da política econômica.

- Professor-Adjunto Contratado do Departamento de Ciências Sociais da Escola de Administração de Emprêsas de São Paulo, da Fundação Getúlio Vargas.

R. Adm. Emp., Rio de Janeiro, 9 (2): 7-36, abr./jun. 1969 
O progresso de uma emprêsa através da elevação de seus níveis de produtividade não deve restringir-se apenas a um acréscimo de bens ou valôres produzidos que, por sua vez, irão aumentar os lucros e dividendos dos proprietários ou acionistas, mas deve repercutir no ambiente sociocultural em que ela desenvolve suas atividades; à medida que ela prospera e progride econômicamente, aumentando sua produção e, portanto, seus lucros, cabe-lhe a responsabilidade de contribuir decisivamente para o bem-estar de seus trabalhadores e, em escala maior, da comunidade local ou regional onde está inserida. Isto porque, indubitàvelmente, "... entre todos os fatôres que desempenham papéis relevantes no crescimento econômico, nenhum é mais importante do que o potencial humano". 1

O trabalho ora apresentado, que visa a analisar alguns aspectos da mão-de-obra e seu relacionamento com diferentes níveis de produtividade na Indústria Siderúrgica Brasileira, constitui parte de um projeto mais amplo de pesquisa, patrocinado pela OEA (Organização dos Estados Americanos) e seu Centro Interamericano de Ciências Administrativas, executado por um grupo de professôres da Escola de Administração de Emprêsas de São Paulo da Fundação Getúlio Vargas, durante o anos de 1965/66. ${ }^{2}$

Os dados e informações estatísticas aqui apresentados permitem, a nosso ver, uma série de inferências e projeções sôbre o crescimento dêsse setor vital para a economia do País, e sôbre o papel que cabe, neste processo, à formação e ao constante aperfeiçcamento da mão-de-obra, em seus diferentes níveis.

\section{Siderurgia. Indústria de Base}

A indústria siderúrgica constitui, sem dúvida, um dos setores básicos da economia brasileira e sua produção é um dos fatôres mais importantes para os planos e a política de desenvolvimento nacional.

De fato, desde a implantação da indústria siderúrgica no país até recentemente, o volume de produção de aços em lingotes, laminados, etc., embora em elevação constante, não alcançou o nível esti-

1 Harbison, F. e Myers, Ch. A. Educação, Mão-de-Obra e Crescimento Econômico, Rio de Janeiro, Editôra Fundo de Cultura, 1965.

2 Balcão, Yolanda Ferreira. Organização e Produtividade na Indústria Siderúrgica Nacional, Revista de Administração de Emprêsas, vol. VIII, n. ${ }^{\circ} 28$, setembro de 1968. 
mado de consumo do país, tornando-se necessária a importação de quantidades elevadas de aço, a fim de atender-se à demanda interna. (Vide Quadro 1).

QUADRO 1:

Produção e Consumo de Aço em Lingotes - 60/65

$1.000 t$

\begin{tabular}{rrrcr}
\hline & $\begin{array}{c}\text { Produção } \\
\text { Nacional }\end{array}$ & Importação & Exportação & $\begin{array}{c}\text { Consumo } \\
\text { Aparente }\end{array}$ \\
\hline 1960 & 2.279 & 553 & 15 & 2.822 \\
61 & 2.485 & 433 & - & 2.918 \\
62 & 2.557 & 385 & - & 2.942 \\
63 & 2.812 & 1.007 & 18 & 3.801 \\
64 & 3.044 & 624 & 164 & 3.054 \\
65 & 2.978 & 532 & 616 & 2.894 \\
\hline
\end{tabular}

Fontes: Relatório do Banco do Brasil, 1963 e Anuário Estatístico do Brasil, 1966 - IBGE.

Conforme o Quadro 1, os respectivos índices de consumo per capita de aço no Brasil continuam a situar-se em nível muito baixo, em relação a alguns países latino-americanos e, sobretudo, quando comparados com as potências industriais mais desenvolvidas.

De acôrdo com os cálculos mais otimistas, o consumo de aço per capita no Brasil não ultrapassa 50 quilos, enquanto nos países mais adiantados chega a cêrca de 600 quilos.

Em diversos estudos realizados por organizações nacionais e internacionais, procurou-se estimar e projetar a demanda futura de produtos siderúrgicos no mercado nacional, bem como a capacidade de produção das emprêsas nacionais, a fim de diminuir-se gradualmente a dependência das importações de produtos-base para a industrialização.

Em conseqüência, foi elaborada uma série de estudos e projetos que - além de completar e ampliar as obras e instalações das siderurgias atualmente em fase inicial de funcionamento (USIMINAS, COSIPA, etc.), cuja produção deve alcançar o nível de $1.000 .000 \mathrm{t}$ /anuais, a fim de apresentar um indice de rentabilidade — visam à cria- 
ção de novos estabelecimentos siderúrgicos (COSIGUA, USIBA, COSINOR, etc.), que deverão atender, principalmente, à demanda regional. E de estranhar, todavia, que os planos, projeções e projetos específicos apresentados se preocupem ùnicamente com os aspectos materiais e financeiros do problema, ou seja, capitais, equipamentos, matérias-primas necessários para chegarem a níveis de produção mais satisfatórios, sem, todavia, dispensarem a devida atenção ao problema do preparo e da adequação de uma fôrça de trabalho tècnicamente treinada e qualificada para as tarefas específicas da produção e da manutenção do equipamento. Fato tanto mais curioso quando se sabe que as escolas técnicas e superiores, que formam anualmente pequenos contingentes de especialistas, estão longe de acompanhar os planos de expansão das emprêsas do setor através de um planejamento sincronizado de ampliação de sua capacidade. Esse hiato entre a provável procura e possível oferta de mão-de-obra deixa prever não sòmente índices baixos de produtividade, como, também, o estrangulamento dos próprios planos de expansão, com consequientes atrasos e prejuízos para as emprêsas e a economia nacional.

\section{O Planejamento dos Recursos Humanos}

Nas últimas décadas, nos países industrialmente desenvolvidos, o planejamento dos recursos humanos tem merecido atenção crescente por parte dos responsáveis pela política econômica da nação. Isso se deve ao reconhecimento de que o problema-chave do desenvolvimento não se resume em quantidade crescente de capital, e sim na aplicação produtiva dêste por homens com conhecimento, experiência e treinamento suficientes para montarem, operarem e desenvolverem as emprêsas em que os recursos estejam sendo empregados. Sòmente através de um planejamento sincronizado e concomitante será possível adequar a expansão dos diferentes setores da economia às necessidades futuras da nação, porque, conforme nos mostra a realidade, a formação e o treinamento de uma mão-de-obra habilitada e qualificada exige tanto se não mais tempo do que a construção e instalação das emprêsas, sobretudo no caso aqui considerado - a siderurgia. Geralmente, os planos de expansão econômica são feitos por um 
período não superior a cinco anos, enquanto planos para a formação, o treinamento e o aperfeiçoamento de recursos humanos necessitam de prazos mais longos, ou seja, pelo menos de dez anos.

O planejamento dos recursos humanos nunca deve restringir-se apenas aos aspectos quantitativos; o progresso tecnológico exige imperiosa e constantemente novas e mais diversificadas qualificações e especialidades que imprimam ao plano também certas características qualitativas.

É fato incontestável que o fator fundamental, responsável pela elevação dos índices de produtividade, é o humano. Todos os outros fatôres de produção são apenas instrumentos, materiais e equipamentos passivos nas mãos dos operários, técnicos e administradores. Nas oito emprêsas, estudadas e analisadas com o fim de se compararem seus respectivos índices de produtividade, encontramos diferenças significativas que não podem ser atribuídas sòmente ao equipamento, localização ou dimensões diferentes.

A formação profissional dos trabalhadores, o nível educacional da mão-de-obra e dos dirigentes, a remuneração do trabalho sob forma de salários e diversos benefícios, enfim, o clima social prevalecente na emprêsa, que cria e estimula a disposição para empenho, responsabilidade e eficiência, tudo isso influi predominantemente nos resultados econômicos e financeiros dos respectivos empreendimentos.

\section{Caracterização das Emprêsas Estudadas}

Os dados que apresentamos, em seguida, não são completes. Nem sempre foi possível obtê-los para os cinco anos (1960-1964) a que se refere o estudo. Todavia, ainda assim é possível compará-los entre si e dêles extrair algumas conclusões sôbre os fatôres que afetam os diferentes níveis de produtividade.

Conforme indica o Quadro 2, apenas três emprêsas foram fundadas antes de 1930 e mais duas outras, tôdas de iniciativa privada, antes da Segunda Guerra Mundial. A capacidade de produção relativamente pequena dessas emprêsas, insuficiente para atender ao mercado interno e à necessidade de capitais vultosos para a construção de novas, provocou a entrada do poder público no setor de siderurgia, durante os anos de guerra, com a fundação de duas emprêsas, E e $\mathrm{H}$, cuja 
QUADRO 2:

Classificação das Emprêsas Estudadas, Segundo Ano de Fundação, Origem do Capital e Número de Empregados, em 1964

\begin{tabular}{|c|c|c|c|c|c|c|}
\hline 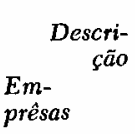 & $\begin{array}{c}\text { Ano de } \\
\text { Fundação }\end{array}$ & $\begin{array}{c}\text { Capital em } \\
\text { dez. } 1966 \\
\text { em NCr\$ } \\
1.000 .000\end{array}$ & $\begin{array}{l}\text { Origem } \\
\quad \text { do } \\
\text { Capital }\end{array}$ & $\begin{array}{c}\text { Organização } \\
\quad \text { da } \\
\text { Emprêsa }\end{array}$ & $\begin{array}{c}\text { Ton. de Aço } \\
\text { Acabado } \\
\text { Produzidas } \\
\text { em 1964 }\end{array}$ & $\begin{array}{c}\text { Num. Apro } \\
\text { ximado de } \\
\text { Empregado } \\
\text { em 1964 }\end{array}$ \\
\hline A & 1924 & 12,0 & $\begin{array}{c}100 \% \\
\text { nacional } \\
100 \%\end{array}$ & Familiar & 70.000 & 2.200 \\
\hline B & 1938 & 15,5 & $\begin{array}{c}\text { nacional } \\
100 \%\end{array}$ & Familiar & 70.000 & 2.400 \\
\hline C & 1925 & - & $\begin{array}{c}\text { nacional } \\
100 \%\end{array}$ & Familiar & 40.000 & 2.000 \\
\hline D & 1937 & 15,0 & $\begin{array}{c}\text { nacional } \\
100 \%\end{array}$ & $\underset{\text { Propr. }}{\text { Familiar }}$ & 70.000 & 2.000 \\
\hline E & 1944 & 97,5 & $\begin{array}{c}\text { nacional } \\
100 \%\end{array}$ & $\begin{array}{c}\text { Estatal } \\
\text { Soc. Anôn. }\end{array}$ & 50.000 & 4.900 \\
\hline $\mathbf{F}$ & 1952 & 40,2 & $\begin{array}{l}\text { estrangeiro } \\
100 \%\end{array}$ & $\begin{array}{c}\text { Privada } \\
\text { Soc. Anôn. }\end{array}$ & 160.000 & 4.700 \\
\hline G & 1921 & 98,0 & $\begin{array}{c}\text { estrangeiro } \\
100 \%\end{array}$ & $\begin{array}{l}\text { Privada } \\
90 \% \text { Prop. }\end{array}$ & 340.000 & $\mathbf{7 . 7 0 0}$ \\
\hline$\underset{\text { TOTAL }}{\mathrm{H}}$ & $\begin{array}{c}1941 \\
-\end{array}$ & $\begin{array}{l}138,7 \\
416,9\end{array}$ & $\begin{array}{c}\text { nacional } \\
-\end{array}$ & $\begin{array}{c}\text { Estatal } \\
-\end{array}$ & $\begin{array}{r}880.000 \\
1.680 .000\end{array}$ & $\begin{array}{l}14.200 \\
40.100\end{array}$ \\
\hline
\end{tabular}

soma de capitais, em 1966, foi superior à das seis emprêsas privadas reunidas.

Existe uma correlação significativa entre o número de empregados, volume de produção e capital nominal das quatro primeiras emprêsas, tôdas elas de dimensão pequena e propriedade de famílias fechadas, sem maiores possibilidades, portanto, de mobilizarem os recursos financeiros necessários no mercado privado de capitais, para os investimentos indispensáveis à ampliação.

Seus índices parciais e globais de produtividade são, aproximadamente, iguais, conforme podemos constatar nos Quadros 3 e 4 .

Quanto às duas emprêsas $\mathrm{E}$ e $\mathrm{H}$, propriedades do poder público, seus indices de produtividade se encontram nos extremos opostos nos Quadros 3 e 4: a emprêsa $E$ aparece como a mais fraca e $\mathbf{H}$, indubitàvelmente, com os melhores índices do grupo todo.

No Quadro 3, representamos - embora com dados incompletos, por não abrangerem tôdas as seis emprêsas - alguns índices diretos de produtividade da mão-de-obra. Constata-se a superioridade das 


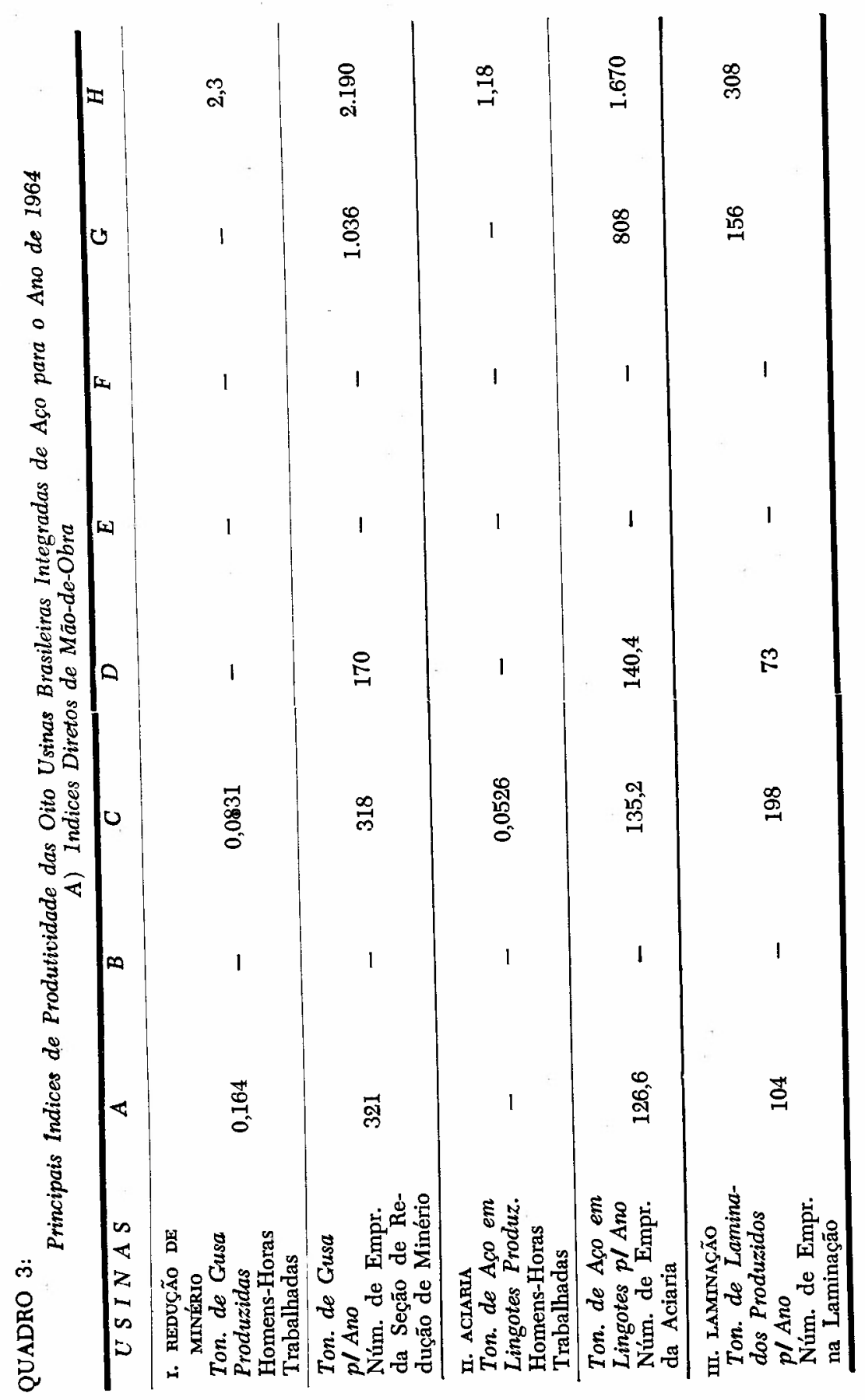


usinas $\mathrm{G}$ e $\mathrm{H}$, em relação às outras menores, sendo seus índices substancialmente mais altos do que os das usinas pequenas. Apenas no setor de laminação os índices de tôdas as usinas se aproximam, mantendo, todavia, a usina $\mathrm{H}$ o primeiro lugar, com um índice que oscila entre $55,5 \%$ e $322 \%$ a mais do que o das outras emprêsas.

\section{QUADRO 4:}

Principais Indices de Produtividade das Oito Usinas Brasileiras Integradas de Aço para o Ano de 1964

B) Indices Integrados de Mão-de-Obra

\begin{tabular}{lllllllllll}
\hline USINAS & $A$ & $B$ & $C$ & $D$ & $E$ & $F$ & $G$ & $H$ \\
\hline $\begin{array}{l}\text { a) } \\
\text { Ton. Laminados } \\
\text { Produz. p/Ano }\end{array}$ & & & & & & & & & & \\
\hline $\begin{array}{l}\text { Núm. Total de } \\
\text { Empr. na Emprêsa }\end{array}$ & & 30,9 & 31,7 & 17,7 & 35,9 & 9,86 & 34,6 & 44,5 & 61,8 \\
\hline
\end{tabular}

b) (em milhões

Faturamento de NCr\$)

Núm. Total de $4,617-3,103 \quad 5,550-7,768 \quad 6,990 \quad 12,520$

Empr. na Emprêsa

Do mesmo modo, embora em proporções menores, os índices integrados de produtividade de mão-de-obra mostram uma vantagem bastante expressiva da emprêsa $\mathrm{H}$ em relação às outras. $\mathrm{O}$ número de toneladas de laminados produzidas por empregado - com exceção das usina $\mathrm{C}$ e $\mathrm{E}$, cujas taxas estão muito abaixo da média, enquanto as outras usinas ostentam índices que oscilam em redor de 30 toneladas por empregado — alcança 44,5 toneladas na emprêsa $\mathrm{G}$ e 61,8 toneladas na $\mathrm{H}$.

Finalmente, ainda no Quadro 4, observamos que o faturamento por número de empregados nas emprêsas pequenas ( $A, C$ e $D$ ) é sensìvelmente inferior ao mesmo índice nas emprêsas $F$ e $G$ e, sobretudo, 
ao da emprêsa $\mathrm{H}$, que supera a tôdas as outras, de $61 \%$ (sôbre a emprêsa $\mathrm{F}$ ) até $340 \%$ (sôbre a emprêsa $\mathrm{C}$ ).

\section{A Mão-de-Obra nas Oito Emprêsas Siderúrgicas}

\section{Indices Diretos e Indiretos de Produtividade da Mão-de-Obra}

As diferenças notadas nos índices de produtividade diretos e indiretos refletem, sem dúvida, a influência e atuação de diversos fatôres, tais como: quantidade e qualidade do equipamento empregado, tecnologia aplicada no layout e fluxo dos materiais e das operações. Tentaremos, todavia, em nosso trabalho, ressaltar a importância do fator mão-de-obra, seu nível educacional, sua habilitação profissional e suas relações com a administração e direção da emprêsa, como variável importante na combinação de todos os fatôres acima mencionados, com o objetivo de alcançar altos níveis de produção e de produtividade.

Os contingentes de mão-de-obra nas emprêsas ora estudadas pouca alteração sofreram no qüinquiênio 1960-1964.

Segundo os dados do Quadro 5, podemos classificar as primeiras quatro (A, B, C e D) como pequenas emprêsas com, aproximadamente, 2.000 empregados cada uma; as três seguintes ( $E, F$ e $G$ ) como médias, entre 4.500 e 7.000 empregados, e $\mathrm{H}$ como emprêsa grande com mais de 10.000 empregados.

Entretanto, mais significativos do que os índices quantitativos são os que informam sôbre a composição qualitativa do corpo dos funcionários de cada emprêsa, dividindo-os, para êste fim, em empregados e operários, técnicos de nível médio e técnicos de nível superior. (Vide Quadro 6).

A emprêsa $A$ dispõe de técnicos de nível superior na proporção de apenas $0,9 \%$ do total de seus empregados, e a mesma percentagem é dada para os técnicos de nível intermediário.

Para a emprêsa $\mathrm{C}$, os respectivos índices são de $1,4 \%$ e $0,3 \%$.

A emprêsa $\mathrm{F}$ apresenta proporção de $0,7 \%$ e $0,9 \%$ para as respectivas categorias.

Admitindo-se como proporção adequada e desejável de técnicos de nível intermediário, em relação aos de nível superior, 3:1, sòmente 


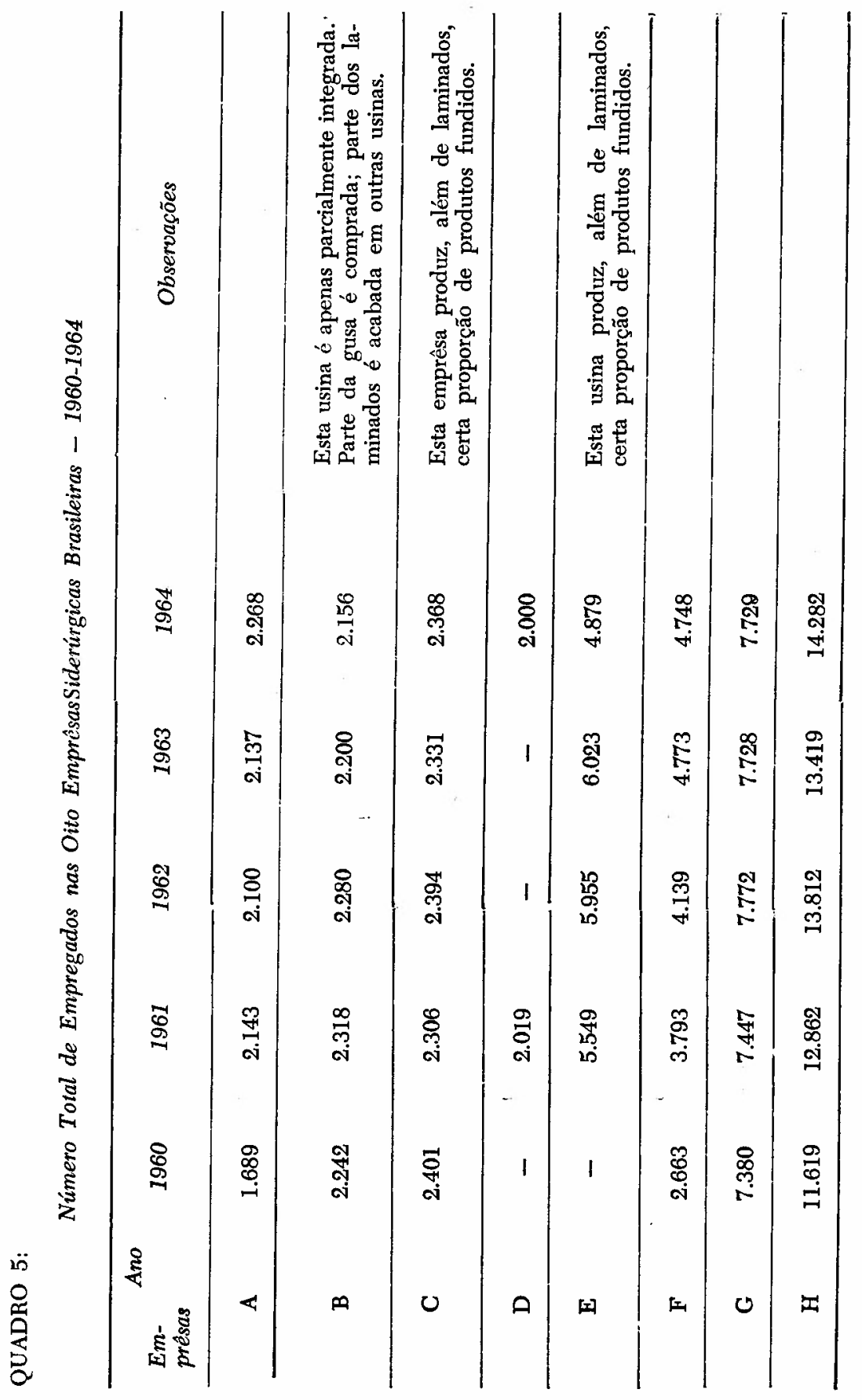




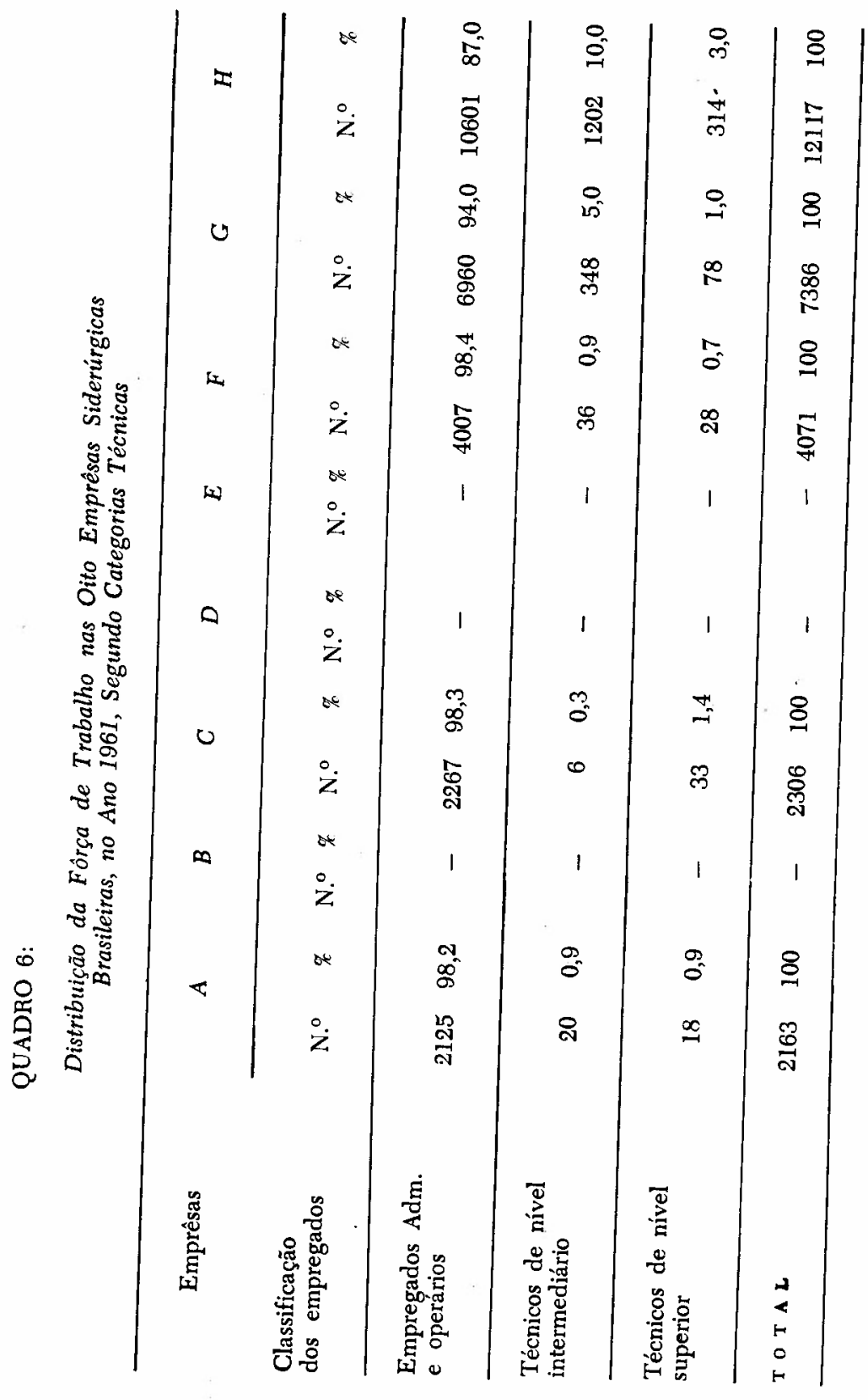


as emprêsas $\mathrm{G}$ e $\mathrm{H}$ preenchem essa condição, sendo, todavia, os números proporcionais dessa última emprêsa substancialmente mais elevados ( $3 \%$ e $10 \%$ do total) do que de tôdas as outras.

O elevado número de técnicos, engenheiros e administradores de nível superior não influi, necessàriamente, no sentido de onerar demasiadamente a fôlha de pagamentos, conforme apreendemos do Quadro 7.

QUADRO 7:

Indices Diretos de Măo-de-Obra

\begin{tabular}{ccccccccccc}
\hline$U$ S I N A S & $A$ & $B$ & $C$ & $D$ & $E$ & $F$ & $G$ & $H$ \\
\hline $\begin{array}{c}\text { Total de Salários } \\
\begin{array}{c}\text { Faturamento } \\
\text { em } \%\end{array}\end{array}$ & 25,3 & - & 28,6 & - & $25,7^{*}$ & $13,3^{*}$ & $16,9^{* *}$ & 11,63 \\
\hline
\end{tabular}

Núm. Total de Operários

Núm. Total de $87,4 \quad-93,7 \quad-\quad-\quad-\quad 85,258,1$

Empregados em $\%$

- Indices referentes ao ano de 1963.

* Indices referentes ao ano de 1961 .

A proporção de funcionários não operários chega a $41,9 \%$ na emprêsa $H$, contra $14,8 \%$ na $G, 6,3 \%$ na emprêsa $C$ e $12,6 \%$ na emprêsa $\mathbf{A}$, supondo-se que a elevada percentagem de empregados não diretamente relacionados com a produção se localiza nos setores de administração, vendas e nos diversos setores de benefícios e serviços assistenciais proporcionados pela emprêsa aos seus empregados. Todavia, longe de reduzir com isso a produtividade e a rentabilidade do investimento, constatamos que a fôlha de pagamentos totaliza apenas $11,63 \%$ do faturamento global da emprêsa $\mathrm{H}$, contra $28,6 \%$ na $\mathrm{C}$ e $25,3 \%$ na $\mathrm{A}$.

As diferenças se tornam ainda mais significativas quando verificamos que, durante todos os cinco anos sôbre os quais se estende o 
estudo, a emprêsa $H$ pagou sempre o salário médio mais alto. (Vide Quadro 8).

QUADRO 8:

Média Anual de Salários Per Capita Pagos nas Usinas Siderúrgicas Brasileiras; 1960-1964; em NCr\$

\begin{tabular}{|c|c|c|c|c|c|}
\hline $\begin{array}{l}\text { Em- } \\
\text { prêsa }\end{array}$ & 1960 & 1961 & 1962 & 1963 & 1964 \\
\hline $\mathbf{A}$ & $\mathrm{I} 47,00$ & 223,90 & 345,70 & 623,30 & $1.168,40$ \\
\hline B & - & - & - & - & - \\
\hline C & 120,50 & 166,00 & 257,00 & 430,00 & 887,00 \\
\hline $\mathrm{D}$ & - & - & - & - & - \\
\hline $\mathrm{E}$ & - & - & - & - & - \\
\hline $\mathbf{F}$ & - & - & 317,40 & 540,00 & - \\
\hline G & 183,00 & 241,70 & - & - & - \\
\hline $\mathbf{H}$ & 215,30 & 287,70 & 463,80 & 803,00 & $1.468,00$ \\
\hline
\end{tabular}

Resumimos, portanto, esta primeira parte, com as seguintes constatações:

a) a emprêsa $\mathrm{H}$ apresenta os índices de produtividade diretos e indiretos mais elevados;

b) $\mathrm{H}$ é a emprêsa com a mais alta proporção de empregados nãooperários;

c) H é a emprêsa com a mais alta proporção de técnicos de nível superior $(3 \%)$ e de técnicos de nível intermediário (10\%);

d) H pagou durante os cinco anos - 1960-1964 — os salários médios mais altos;

e) ainda assim, a proporção dos salários, em relação ao faturamento global, é o mais baixo $(11,63 \%)$ de tôdas as emprêsas. 
A eficiência e, portanto, a sobrevivência das emprêsas estão condicionadas, invariàvelmente, à solução de um problema fundamental, ou seja, a existência de um corpo de funcionários habilitados e capacitados para as tarefas específicas a êles confiadas na organização, em seus diversos níveis e setores.

A importância da mão-de-obra qualificada para o desenvolvimento - o qual no fundo, não é outra coisa que o aumento de produtividade global de uma nação - é amplamente reconhecida por dirigentes e administradores das emprêsas, nos países industrialmente avançados.

Nos países em via de desenvolvimento, todavia, muitas emprêsas ainda carecem de uma política consciente e eficaz de desenvolvimento dos recursos humanos, através da qual se procure elevar o nível de conhecimentos, de habilitação e de capacidade profissional da mão-de-obra .

Verdade é que o assunto é sujeito a polêmica: afirmam muitos empresários e administradores que os custos de tais programas de formação de mão-de-obra são elevados demais para a emprêsa individual arcar com as despesas sòzinha, devendo caber essa tarefa ao poder público, exclusivamente. Entretanto, conforme demonstram os próprios índices comparativos de produtividade, o investimento em educação dos empregados é altamente lucrativo e, embora nem sempre seja possível quantificar exatamente o retôrno dêsse investimento, êle se constitui num dos processos mais eficientes de acumulação de capital humano.

A pergunta referente ao nível de instrução dos empregados não foi respondida satisfatòriamente pela maioria das emprêsas ora estudadas. Todavia, em dois casos, os dados fornecidos são significativos: na emprêsa $\mathrm{A}$, apenas $20 \%$ dos operários têm instrução primária, outros $20 \%$ aproximadamente sabem assinar seu nome e os restantes $60 \%$ são analfabetos.

$\mathrm{Na}$ emprêsa $\mathrm{C}$, os índices são os seguintes: $8,1 \%$ analfabetos, $1,6 \%$ com instrução secundária e $89 \%$ com instrução primária. As duas emprêsas acima não mantêm curso de alfabetização para seus fun- 
cionários, muito embora a emprêsa A tivesse tentado implantar um, logo abandonado por falta de receptividade.

\section{Formaçâo Técnica e Profissional de Mão-de-Obra}

Esses dados contrastam sobremaneira com outros, colhidos em fontes secundárias sôbre as emprêsas $F$ e $\mathrm{G}$ (estrangeiras) e $\mathrm{E}$ e $\mathrm{H}$ (estatais). A emprêsa $E$ proporcionou auxílio e manteve parcialmente, em 1964, uma rêde escolar que contava com 7.553 alunos e 198 professôres, distribuídos numa Escola de Formação Profissional, com 18 cursos de aprendizes de ofício, 10 cursos práticos, 5 grupos escolares e 39 escolas rurais. Manteve ainda um Colégio Técnico Industrial de Metalurgia, que visava à formação de técnicos altamente especializados em operações de siderurgia.

A emprêsa $F$, em convênio com o SENAI, manteve cursos de aprendizagem para 69 jovens, nas seguintes especialidades:

- Mecânicos de Manutenção

- Torneiro-Mecânico

- Mecânico-Eletricista

- Mecânico-Ferramenteiro

- Mecânico-Ajustador

- Ferreiro.

Ademais, diversos cursos para administradores, como

- Organização de Trabalho e Custos de Produção

- Chefia de Pessoal

- Custos Industriais

- Técnico de Metalurgia, etc.

foram por ela desenvolvidos e realizados.

A emprêsa G, a mais antiga das que fazem parte dêste estudo, construiu e mantém uma série de escolas primárias e cursos de ensino profissional, apoiando ainda financeiramente os ginásios nas cidades onde estão situados seus estabelecimentos.

Proporciona, também, bôlsas de estudos a alunos que frequientam o ensino técnico, em nível médio e superior. 
De tôdas as emprêsas ora estudadas, $\mathbf{H}$ é aquela que apresenta uma verdadeira política educacional, que se estende desde a orientação tecnopedagógica e o auxílio financeiro a escolas primárias e secundárias, por ela construídas, até os cursos noturnos de alfabetização para adultos e, sobretudo, se concentra no ensino profissional, visando a suprir os seus centros de produção e de administração com mão-de-obra altamente qualificada, que possa assegurar a manutenção dos altos níveis de eficiência alcançados na operação e manutenção do equipamento. A emprêsa $\mathbf{H}$ é a única entre as oito emprêsas que, com o plano para expansão de suas atividades produtivas, planeja sincronizadamente a ampliação e o aperfeiçoamento do seu quadro de pessoal técnico e administrativo, proporcionando ensino técnico a mais de 1.500 jovens, anualmente, através de Cursos Industriais Técnicos, Ginásio Industrial, Cursos de Aprendizagem Industrial (em convênio com o SENAI), em diversas localidades onde se situam seus estabelecimentos.

Ademais, a emprêsa mantém, em convênio com uma escola superior, um curso de Engenheiros Metalúrgicos, cujos formandos engenheiros representam fonte valiosa de mão-de-obra altamente qualificada, não sòmente para a emprêsa, como também para os outros estabelecimentos do setor no país.

Em resumo, com tôdas as limitações em virtude da ausência de dados numéricos mais específicos, é lícito concluir que as quatro emprêsas pequenas, de propriedade familiar, não têm, pròpriamente, uma política de desenvolvimento de mão-de-obra, visando a elevar a capacitação técnica e administrativa de seu pessoal. Pelo menos em um dos casos (emprêsa $\mathrm{A}$ ), o problema não se torna grave, a ponto de prejudicar o funcionamento da emprêsa, porque existe um vasto mercado de mão-de-obra no município. Entretanto, frisamos a importância da mentalidade empresarial e administrativa, que saiba dar a devida atenção a êsse aspecto das atividades da emprêsa.

As duas emprêsas cujo capital é de origem estrangeira ( $F$ e $G$ ) mantêm cursos técnicos que parecem atender plenamente às suas próprias necessidades.

São as duas emprêsas de propriedade estatal que desenvolvem os programas quantitativa e qualitativamente mais amplos, no sentido de formação e aperfeiçoamento, não sòmente de sua própria mão-de-obra, 
atualmente empregada em seus estabelecimentos; contribuem levando também a instrução primária, elementar e o ensino secundário e técnico para tôda a população de sua região, beneficiando assim, diretamente, as outras emprêsas e, indiretamente, a economia nacional.

\section{Recrutamento e Seleção de Pessoal}

$\mathrm{O}$ recrutamento e a seleção de pessoal têm importância primordial na política de mão-de-obra das emprêsas, pelo papel que desempenham na distribuição racional dos recursos humanos, entre as diferentes emprêsas e na sociedade em geral.

Depende do serviço de recrutamento e seleção o encaminhamento da mão-de-obra para posições adequadas ao seu talento, conhecimento, experiência e possibilidades de desenvolvimento, enquanto uma colocação inadequada pode gerar, fàcilmente, insatisfação e frustração, cujos efeitos sôbre a produtividade poderão ser desastrosos.

Segundo HALSEY, ${ }^{3}$ recrutamento é o "têrmo comumente aplicado à descoberta e desenvolvimento de boas fontes de fornecimento dos candidatos necessários à organização, de modo a sempre haver um adequado número de propostas de trabalho para tôdas as vagas". Neste sentido, o recrutamento extravaza o âmbito da emprêsa e se estende a uma política consciente de fomento do mercado de trabalho, contribuindo para a formação e a preparação de uma reserva de mão-de-obra qualificada, de interêsse direto ou indireto para a emprêsa.

Entretanto, para o pleno e racional aproveitamento dos contingentes, torna-se necessária uma seleção dos candidatos aos empregos, em vista da necessidade de escolher os melhores para as respectivas tarefas. Um processo de seleção rigorosa e de acôrdo com os critérios científicos representa uma economia futura sob forma de melhor rendimento, menos perdas por estragos de material e máquinas e, sobretudo, um melhor clima social na emprêsa.

Os dados fornecidos pelas emprêsas não permitem comparações quantitativas, quanto aos índices de recrutamento e de seleção; entretanto, são elucidativos quanto aos métodos usados em cada uma.

3 Halsey, G. Handbook of Personnel Management, Nova Iorque, Harper and Brothers, 1947. 
A emprêsa A precede ao recrutamento de empregados por recomendações internas e externas e, às vêzes, recorre a anúncios nos jornais.

A emprêsa $\mathrm{C}$ faz recrutamento direto, isto é, por avisos na portaria $\mathrm{e}$, às vêzes, anúncios nos jornais. Pessoal técnico e administrativo é recrutado nas escolas técnicas e superiores.

A emprêsa $F$ recruta operários não qualificados, qualificados e empregados de escritório, por avisos na portaria, sendo que para estas últimas duas categorias são publicados também anúncios nos jornais. Pessoal técnico e administrativo é procurado nas escolas e através de jornais.

A emprêsa $H$ utiliza as mais variadas e completas formas de recrutamento para os diferentes níveis e categorias de funcionários: rádio e editais para os não qualificados; anúncios nos jornais, recrutamento em escolas técnicas e superiores e editais para operários qualificados, empregados de escritório, pessoal técnico, engenheiros e administradores.

E também nessa emprêsa que a seleção do pessoal, de todos os níveis, é feita através de entrevistas, verificação dos conhecimentos e níveis de escolaridade dos candidatos, seus diplomas e certificados, testes psicológicos e psicotécnicos e, finalmente, por um período de experiência de seis meses. Ademais, a emprêsa procede regularmente à seleção de empregados para fins de reclassificação ou transferência, criando, assim, amplas perspectivas para o progresso profissional de seus funcionários.

As emprêsas A e B não se utilizam de qualquer processo específico e padronizado de seleção dos operários ou empregados de escritório.

A emprêsa $\mathrm{C}$ adota a entrevista como meio de seleção para operários não qualificados; o tempo de experiência para os qualificados; testes psicológicos para empregados de escritório; e certificados e diplomas para pessoal técnico e administrativo.

A emprêsa $F$ realiza entrevistas para tôdas as categorias, testes para empregados de escritório, pessoal técnico e administrativo; avaliação do conhecimento teórico e prático, verificação de diplomas e certificados e período de experiência para todos os níveis. 


\section{Treinamento}

A dinâmica da emprêsa moderna, que provoca constantes mudanças na organização, nos serviços e nos métodos, exige também processos de treinamento contínuo, a fim de preparar e adaptar a mão-de-obra às diferentes tarefas especializadas. $O$ sucesso de uma emprêsa que consegue elevar o nível de produtividade de seus empregados depende, em parte, de um programa adequado e eficiente de treinamento. Novamente, não dispomos de dados quantitativos além dos já enumerados na parte referente ao nível de instrução e às atividades educacionais nas emprêsas. Todavia, as diversas formas e métodos de treinamento, para todos os funcionários, são, invariàvelmente, mais amplos na emprêsa $\mathbf{H}$ que, além de inúmeros cursos próprios de especialização para tôdas as categorias, se utiliza do $T W I$, manda funcionários para estágios e treinamento em outras emprêsas, e mantém convênio com o SENAI.

QUADRO 9:

Formas e Métodos de Treinamento Oferecidos por Quatro Emprêsas $(A, C, F$ e $H$ )

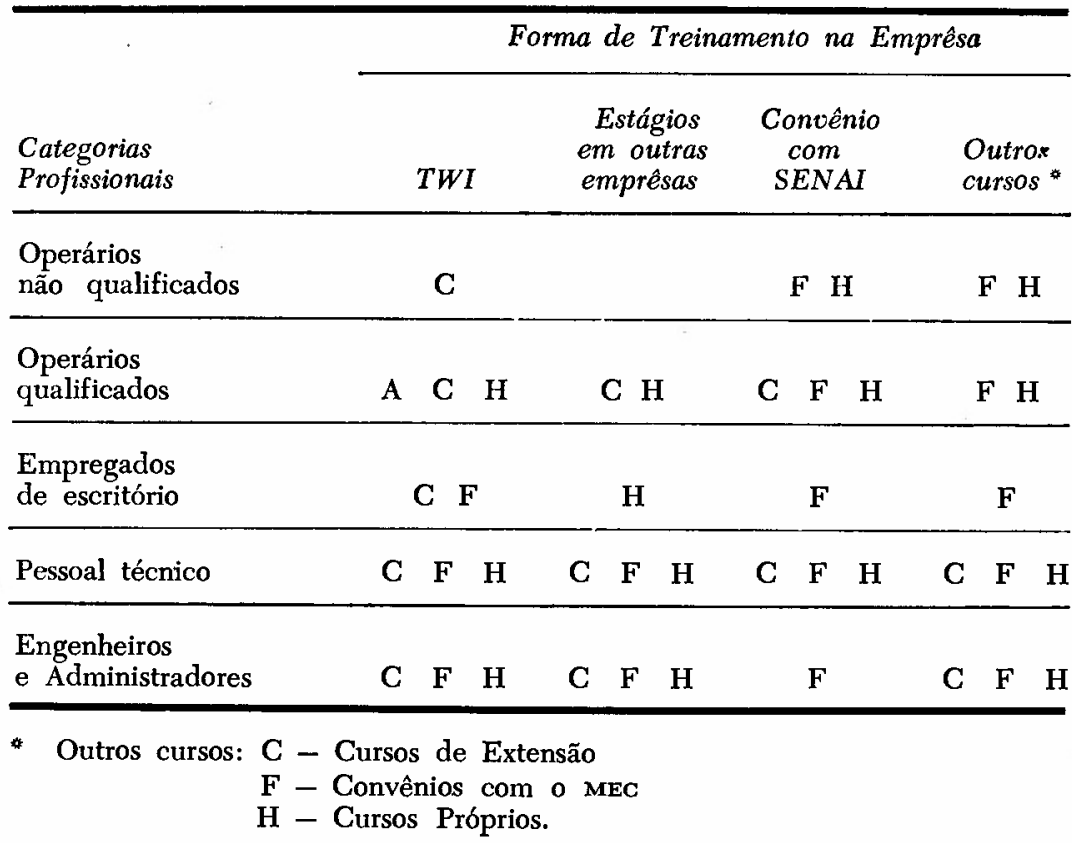

Abril/Junho 1969 
TWI para as categorias de empregados de escritório, técnicos e administradores, convênios com o SENAI e o MEC e, eventualmente, estágios em outras emprêsas para o pessoal técnico são as formas de treinamento utilizadas pelas emprêsas $\mathrm{F}$ e $\mathrm{C}$, enquanto a emprêsa $\mathrm{A}$ não oferece nenhuma dessas facilidades.

No Quad̉ro 9, procuramos apresentar uma visão conjunta das facilidades de treinamento oferecidas pelas quatro emprêsas que responderam a êsse item do questionário.

\section{A Integração do Empregado à Emprêsa}

O nível de instrução e de cultura geral dos seus empregados bem como o treinamento específico são condições necessárias para se conseguirem níveis compatíveis de produtividade na emprêsa. Todavia, o pleno empenho do empregado, em vista de uma produtividade ótima, exige também sua integração social na emprêsa, o ajustamento de sua personalidade às normas e valôres do grupo de trabalho e a aceitação dos objetivos da emprêsa como sendo também seus. A motivação inicial depende da maneira como o empregado está sendo introduzido ao serviço e a seus colegas .

Das quatro emprêsas que responderam à indagação do questionário: "Existe uma rotina definida para a integração de um nôvo empregado à emprêsa?", obtivemos as seguintes respostas:

\section{Emprêsa A}

- nada existe a respeito.

Emprêsa C

- para o nível de supervisor e de chefia é dada uma explicação detalhada do organograma da política empregatícia, dos planos de expansão, das linhas de fabricação e das relações entre os diversos níveis e seções.

\section{Emprêsa $\mathrm{F}$}

- está elaborando um Manual do Nôvo Empregado e pretende iniciar um treinamento introdutório.

Emprêsa $H$

- realiza um amplo programa de orientação geral inicial para todos os níveis. Mantém palestras e sessões audiovisuais sôbre o his- 
tórico da emprêsa, organiza visitas aos diversos departamentos, explica detalhadamente, em sessões cinematográficas, os processos de fabricação, de origem da matéria-prima até ao produto acabado, os planos de expansão, a prevenção de acidentes, etc.

\section{Absenteísmo, Rotatividade da Mão-de-Obra e Freqüiencia $e$ Gravidade de Acidentes de Trabalho}

Altos índices de produtividade dependem, estreitamente, do fluxo contínuo e ininterrupto das atividades produtivas da emprêsa, especialmente no caso de siderurgia. Os atrasos, faltas ou paralisações coletivas do serviço oneram sobremaneira os custos da emprêsa, não sòmente pelos homens/horas de trabalho perdidas diretamente, mas, também, pelos reflexos que possam ter, por exemplo, sôbre as despesas com o treinamento de novos empregados e os outros departamentos, que dependam do fluxo organizado da produção. As sanções aplicadas pela administração da emprêsa, de acôrdo com a legislação trabalhista, geralmente não fazem surtir o efeito desejado, porque são aplicadas cegamente, em função dos sintomas, sem averiguar as causas mais profundas das atitudes negativas dos empregados.

Altas taxas de rotatividade da mão-de-obra, de absenteísmo e de incidência de acidentes são sobretudo indicativos de um péssimo clima social na emprêsa, ou seja, insatisfação, problemas e conflitos. As formas e métodos pelos quais a administração procurará reprimir ou mudar essas atitudes negativas podem, quando não se enquadram numa política geral de relações industriais, agravar ainda mais a situação .

Os Quadros 10, 11 e 12 apresentam os respectivos índices de rotatividade e absenteísmo, bem como os de frequiência e gravidade de acidentes para as três emprêsas ( $\mathrm{A}, \mathrm{C} \mathrm{e} \mathrm{H}$ ) que forneceram informações a respeito.

Quanto aos acidentes e sua gravidade - embora fatôres materiais como layout, iluminação, velocidade das máquinas, vestimentas e utensílios de proteção tenham, sem dúvida, grande influência sôbre sua freqüência - a disposição psíquica do operário no trabalho, sua motivação e satisfação derivada atuam no sentido da redução de inci- 


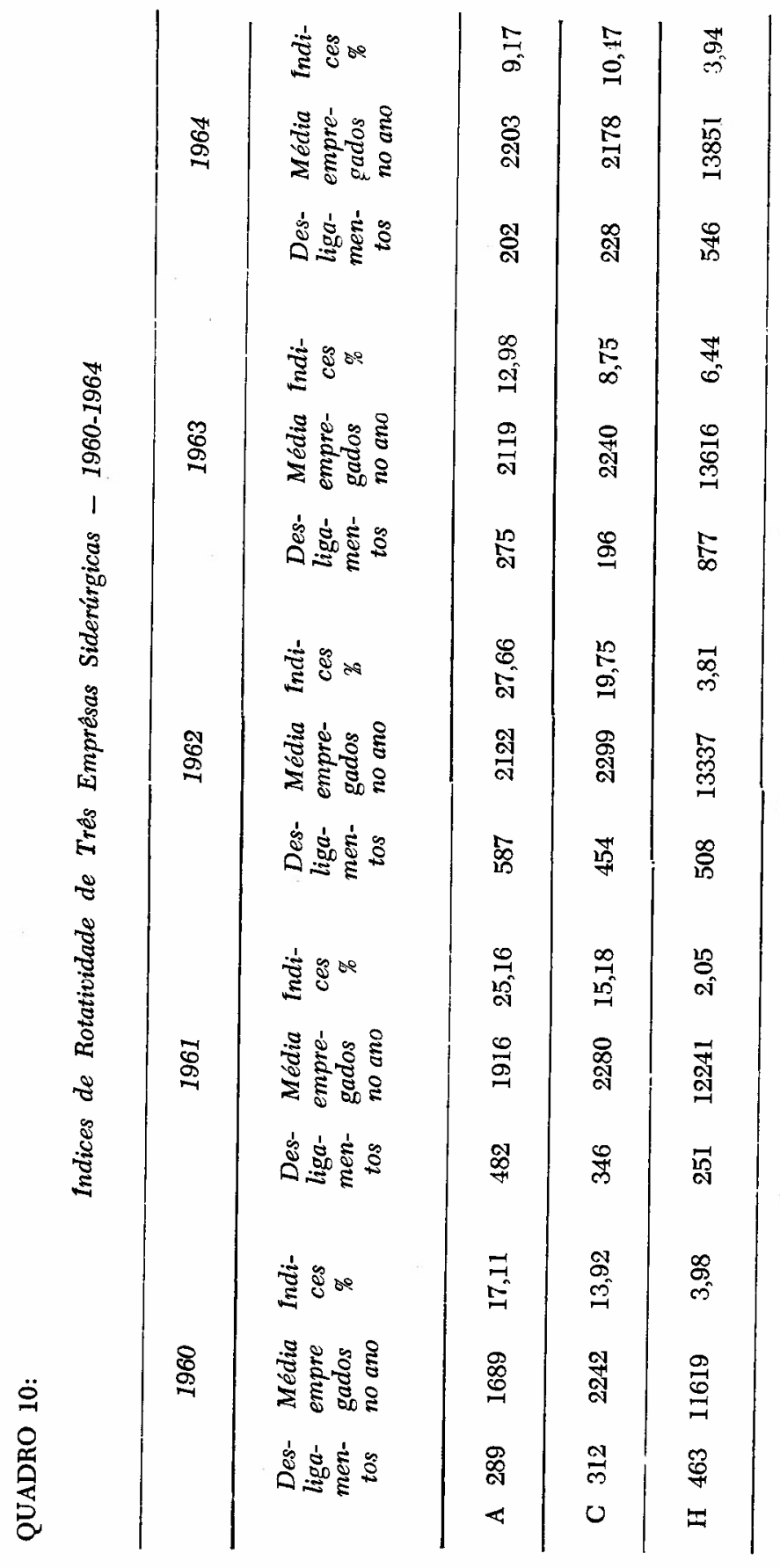


QUADRO 11:

Indices de Absenteísmo de Três Emprêsas Siderúrgicas 1960-1964

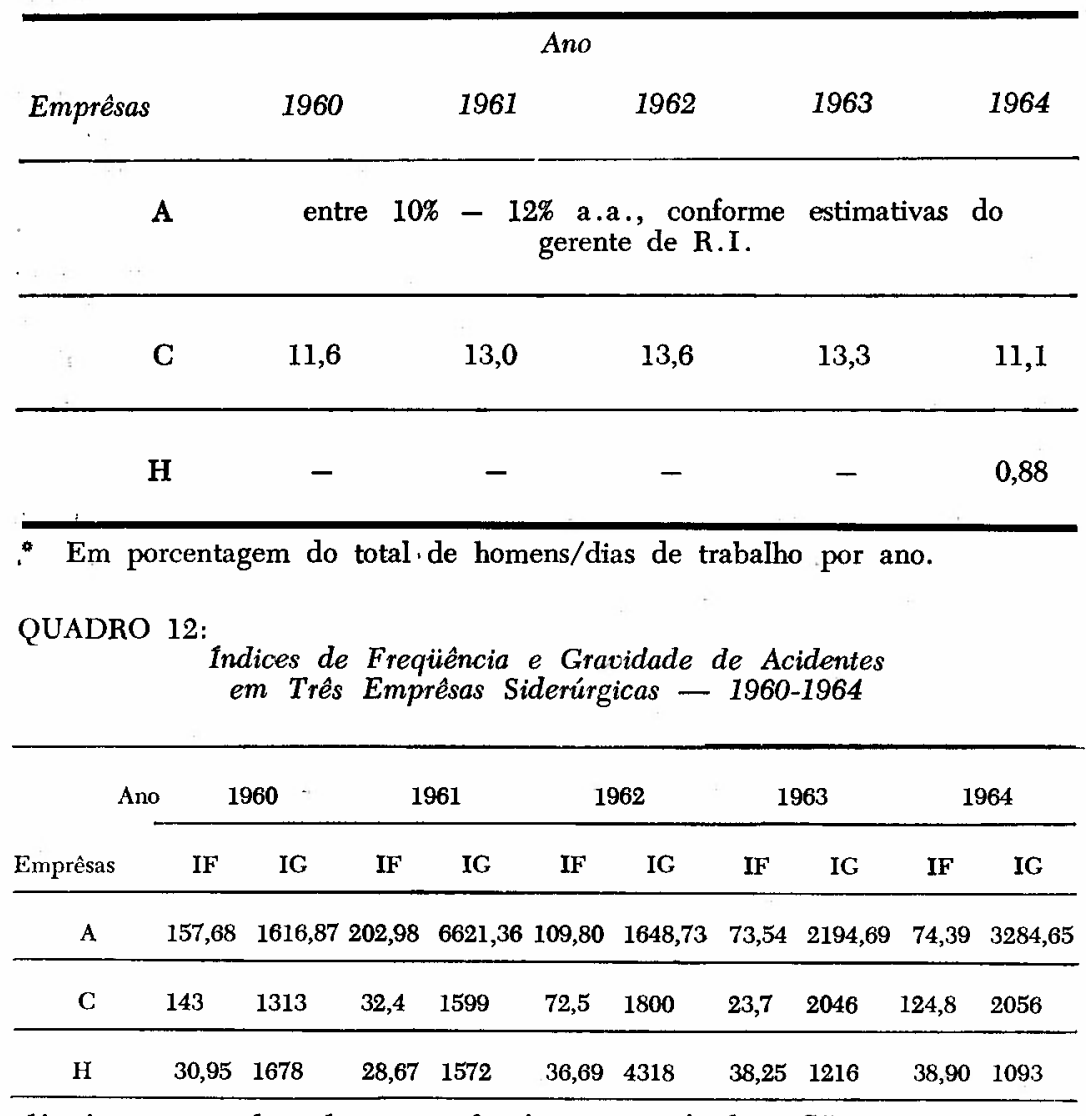

dência, em geral, e dos casos fatais, em particular. São extremamente significativos os índices apresentados pela emprêsa $\mathrm{H}$, em comparação com os de A e C, conforme mostra o Quadro 12 .

\section{Benefícios (Fringe Benefits)}

Tôdas as despesas feitas pela emprêsa com serviços assistenciais, educacionais, médicos, alimentares, etc., em suplemento ao salário básico, são considerados como benefícios (fringe benefits) .

Muito se tem discutido e continua ainda a polêmica sôbre o encargo adicional que representariam para as emprêsas o estabelecimento e 
a manutenção de serviços assistenciais, educacionais e recreativos para os empregados e suas famílias.

Não pode haver dúvida de que essas atividades assistenciais absorvem vultosos recursos e uma parcela da fôrça de trabalho, que, segundo alguns, devem ser melhor aproveitados no próprio processo de produção. Em que pêse a falta de dados para fins de análise e comparação, apenas duas das emprêsas forneceram informações a respeito do montante gasto em despesas com leis e assistência sociais. Em relatório da emprêsa $G$ notamos que, para os anos de 1960 e 1961 , a despesa total para êsses fins chega a $25 \%$ e $30 \%$ da fôlha de pagamentos, enquanto que na emprêsa $F$ essa despesa ultrapassa, em 1965, 40\% do total dos gastos com pessoal, sob forma de salários, ordenados, gratificações e décimo terceiro salário.

$O$ Quadro 13 mostra as despesas com benefícios em porcentagem da fôlha de pagamentos nas emprêsas A e C. Em ambas, os índices são muito inferiores aos das emprêsas $F$ e $G$, acima citados.

QUADRO 13:

Porcentagem das Despesas com Beneficios

\begin{tabular}{cccccc}
\hline & \multicolumn{3}{c}{ Ano } & & \\
Emprêsas & $\begin{array}{c}1960 \\
\%\end{array}$ & $\begin{array}{c}1961 \\
\%\end{array}$ & $\begin{array}{c}1962 \\
\%\end{array}$ & $\begin{array}{c}1963 \\
\%\end{array}$ & $\begin{array}{c}\text { I964 } \\
\%\end{array}$ \\
\hline $\mathrm{A}$ & 27,7 & 4,6 & 13,9 & 10,6 & 9,7 \\
\hline $\mathrm{C}$ & 3,1 & 2,5 & 3,1 & 2,9 & 2,3 \\
\hline
\end{tabular}

Entretanto, embora sem indicações sôbre seu custo monetário, as mais extensas e completas relações de serviços e benefícios prestados são as das emprêsas $\mathrm{E}$ e $\mathrm{H}$, ambas de propriedade estatal. As atividades socioassistenciais desenvolvidas por elas compreendem serviços que visam a atender não sòmente aos empregados, como também a seus familiares e dependentes, em regime de gratuidade. Um elemento fundamental dos benefícios é a assistência habitacional, não sòmente através de locação de residências mediante aluguel barato, mas também financiamento para aquisição de casa própria. Em ambos os casos, as emprêsas, por fôrça de localização das usinas, foram levadas, cada uma, a construir uma cidade para alojar seus 
empregados, com milhares de residências e serviços urbanos completos (energia elétrica, água, esgotos, telefone, escolas, etc.). Além de hospitais, maternidades, clínicas dentárias, etc., essas emprêsas mantêm escolas em diferentes níveis de ensino, postos de abastecimento, e põem em prática un vasto programa educacional-recreativo, concedendo, também, subsídios a clubes sociais e esportivos organizados pelos empregados. (Vide Quadro 14).

QUADRO 14:

Beneficios Oferecidos aos Empregados pelas Emprêsas Siderúrgicas

\begin{tabular}{|c|c|c|c|c|c|c|c|c|}
\hline \multirow{2}{*}{ Beneficios } & \multicolumn{8}{|c|}{ Emprêsas } \\
\hline & $A$ & $B$ & $C$ & $D$ & $E$ & $F$ & $G$ & $H$ \\
\hline Assistência médica & & $\mathrm{x}$ & $\mathrm{X}$ & & $\mathrm{x}$ & $\bar{x}$ & $\mathrm{X}$ & $\bar{x}$ \\
\hline Assistência hospitalar & & & & & $\mathrm{x}$ & & $\mathrm{x}$ & $\mathrm{x}$ \\
\hline Assistência dentária & & & $\mathrm{x}$ & & & & $\mathrm{x}$ & $\mathrm{x}$ \\
\hline Assistência social & & & $\mathrm{x}$ & & $\mathbf{x}$ & $\mathrm{x}$ & & $\mathrm{X}$ \\
\hline Assistência alimentar & & $\mathrm{x}$ & & & $\mathrm{x}$ & $\mathrm{x}$ & & $\mathbf{x}$ \\
\hline Assistência educacional & & & $\mathrm{x}$ & & $\mathrm{x}$ & $\mathrm{x}$ & $\mathbf{x}$ & $\mathbf{x}$ \\
\hline Assistência habitacional & & & $x$ & & $\mathrm{x}$ & & $\mathrm{X}$ & $\mathrm{X}$ \\
\hline Auxílio p/doença & & & & & $\mathrm{x}$ & & $\mathbf{X}$ & $\mathrm{x}$ \\
\hline Auxílio $\mathrm{p} /$ funeral & $\mathrm{x}$ & & & & & & & $\mathbf{x}$ \\
\hline Assistência recreativa & & & & & & & & $\mathrm{x}$ \\
\hline Financ. p/habitação & & & & & & & $\mathrm{x}$ & $\mathrm{x}$ \\
\hline Financ. p/aquis. veículos & & & & & $\mathrm{x}$ & & & $\mathrm{x}$ \\
\hline Esportes & & & $\mathbf{x}$ & & & & $\mathrm{X}$ & $\mathrm{x}$ \\
\hline Transportes & & & & & $\mathrm{x}$ & & $\mathrm{X}$ & $\mathrm{X}$ \\
\hline Cooperativa & $\mathbf{x}$ & & & & & & & $\mathbf{x}$ \\
\hline Clube - praça de esportes & $\mathrm{x}$ & $\mathrm{x}$ & & & $\mathrm{x}$ & $\mathrm{x}$ & $\mathrm{x}$ & $\mathrm{x}$ \\
\hline Farmácia & $\mathbf{x}$ & & & & $\mathrm{x}$ & & & \\
\hline
\end{tabular}

A instalação de serviços de benefícios não significa, a nosso ver, uma orientação altruística da direção da emprêsa ou, como alguns querem, um desperdício dos recursos econômicos e financeiros. Ao contrário, os altos índices de produtividade e os baixos índices de absenteísmo indicam-nos que a extensão dos benefícios aos empregados 
e seus dependentes é uma atitude pragmática, ditada pelas condições peculiares do mercado de trabalho. "Em face da carência de mão-deobra qualificada e estável, os benefícios constituem um chamariz de recrutamento e um instrumento de integração à emprêsa, de elementos vantajosos, profissionalmente, alvos que são de uma procura intensa no mercado de trabalho competitivo". ${ }^{4}$

As emprêsas cuja localização obedece a outros critérios econômicos, independentemente da presença de um mercado de trabalho próximo, são obrigadas a oferecer condições de vida vantajosas e uma mãode-obra cuja origem recente está no meio rural. Para essas massas operárias, migradas do campo, onde viveram ainda de acôrdo com padrões e atitudes de uma fase pré-industrial, impõe-se à emprêsa uma função além da puramente econômica, ou seja, a de ressocialização de sua mão-de-obra através da educação, formação profissional e integração ao estilo de vida urbano-industrial.

\section{Conclusões}

Estabelecer uma relação causal direta entre os índices de produtividade da mão-de-obra e a qualidade do sistema de relações industriais nas oito emprêsas - objeto dêste estudo - não seria possível, em virtude da escassez das informações fornecidas pelas mesmas e, ainda, das falhas e dos dados incompletos que não permitem constituir verdadeiras séries a fim de se estabelecerem comparações entre as emprêsas.

Entretanto, os dados estatísticos compilados nos quadros do texto e nos anexos parecem sugerir as seguintes conclusões:

a) Entre 1960 e 1964, a produtividade média da mão-de-obra em tôdas as emprêsas, medida pela relação tonelada de aço por número total de empregados, não se modificou, pràticamente, tendo inclusive declinado no caso da emprêsa $\mathrm{H}$.

b) No mesmo período, também, o índice integrado de faturamento por número total de empregados, quando confrontado com o aumento do custo de vida ( $561 \%$ conforme Conjuntura Econômica da Fundação Getúlio Vargas), mostra apenas uma melhora fictícia da produtividade, em virtude da inflação.

4 Ratrner, H. Benefícios e Motivação no Trabalho, Revista de Administração de Emprêsas, vol. IV, n. ${ }^{\circ}$ 19, junho de 1966. 
c) Comparando-se os índices das oito emprêsas entre si, ressalta-se a vantagem absoluta da emprêsa $\mathbf{H}$ e, em grau menor, da emprêsa $\mathbf{G}$. d) Essas emprêsas apresentam as mais altas proporções de técnicos de nível intermediário e superior em relação ao total da mão-de-obra entre as oito emprêsas estudadas.

e) A emprêsa $\mathrm{H}$ ostenta os índices mais baixos de absenteísmo, rotatividade de mão-de-obra e frequiência de acidentes.

f) A emprêsa $H$ apresenta o mais completo sistema de relações industriais, visando não sòmente ao recrutamento, formação e treinamento de mão-de-obra, mas também à sua plena integração na emprêsa e na sociedade industrial emergente.

\section{Considerações Finais}

O Brasil ingressou relativamente tarde no setor da siderurgia, numa época em que os contínuos avanços da tecnologia e a severa concorrência internacional impõem padrões de racionalidade e eficiência de produção, dificilmente realizáveis por emprêsas que não podem cumprir economias de escala.

O tamanho ideal de uma usina siderúrgica, de acôrdo com as exigências da tecnologia moderna, corresponde a uma capacidade de produção de três a quatro milhões de toneladas de lingotes de aço por ano. De fato, assistimos, nos últimos anos, a um movimento ininterrupto de fusões e associações de emprêsas siderúrgicas na Europa Ocidental, visando, com isso, à sua maior racionalização e eficiência, em face do poder competitivo dos gigantes norte-americanos. O consumo brasileiro global, entretanto, oscilou entre 1960 e 1964, anos a que se estende a pesquisa, entre 2,1 e 2,6 milhões de toneladas de aço, de modo que se torna perfeitamente ilusória a aspiração a altos índices de produtividade da indústria siderúrgica nacional, como um todo.

Sob êsse aspecto, as oito emprêsas ora estudadas, que representavam, em 1964, aproximadamente $80 \%$ da capacidade produtiva instalada, refletem singularmente as condições e as perspectivas do desenvolvimento dêsse setor básico da indústria nacional.

Tôdas elas - com exceção da emprêsa $H$ - podem ser consideradas como emprêsas grandes em têrmos absolutos e inseridas 
no contexto econômico brasileiro. Comparadas, todavia, aos estabelecimentos congêneres no mundo, são pequenas, ineficientes e sofrem de uma série de problemas de difícil solução a curto ou médio prazo. Escalas de produção insuficientes, agravadas por um mercado consumidor oscilante, a falta de organização e planejamento racionais, a necessidade de investimentos pesados para ampliação e modernização das instalações, diante de um mercado de capitais apenas incipiente e, finalmente, a carência absoluta de mão-de-obra qualificada, em todos os escalões, são apenas alguns aspectos do dilema que enfrenta a indústria siderúrgica no Brasil.

Nos diferentes estudos sôbre a siderurgia brasileira, realizados por emprêsas de consultoria nacionais e estrangeiras, nos últimos anos, surge uma série de recomendações, tais como:

a) necessidade de concentrar a produção siderúrgica em complexos integrados, bastante grandes, para operarem a baixo custo;

b) formação de um holding das diferentes emprêsas de propriedade estatal, visando a uma uniformização de sua política comercial;

c) eliminação paulatina das emprêsas não-produtivas; etc.

Não podemos entrar no mérito dessas recomendações no âmbito restrito dêste trabalho. Queremos apenas ressaltar um aspecto freqüentemente omisso nos relatórios apresentados e que reputamos essencial para todos os planos de desenvolvimento siderúrgico.

Não pode haver dúvida de que o aumento da produção siderúrgica e do consumo per capita de aço constitui fator poderoso de aceleração do desenvolvimento econômico. Entretanto, os cálculos mais cautelosos indicam a necessidade de um investimento inicial de US\$ 400 a 500 por tonelada a ser produzida, entendendo-se esta importância como correspondente ao equipamento e às instalações do estabelecimento, sem tomar em consideração as somas adicionais necessárias para a construção de habitações, escolas, abastecimento de água, etc., nos núcleos residenciais a serem erigidos para a mãode-obra, sem falar de sua formação profissional, treinamento e aperfeiçoamento constantes.

Diante da exigüidade dos recursos e da reconhecida resistência de capitalistas, nacionais ou estrangeiros, em investirem num setor cuja 
rentabilidade é baixa e a longo prazo, seria de interêsse das emprêsas e do País seguir um caminho diferente, ou seja, dar prioridade ao aprimoramento da mão-de-obra, medida essa bem menos onerosa do que os pesados investimentos em bens de capital, necessários à modernização do equipamento.

O desempenho superior de operários com formação técnica e bom treinamento tem efeitos imediatos no sentido de elevar a produtividade e, assim, a rentabilidade da emprêsa, enquanto o uso de máquinas das mais modernas por pessoa iletrada e sem qualificação técnica suficiente resultará em baixa produtividade e desperdício de recursos escassos e preciosos.

Eis, portanto, um caminho que os resultados de nosso estudo parecem sugerir.

ANEXO I:

Indices Integrados de Produtividade de Mão-de-Obra

Toneladas de aço em lingotes produzidos anualmente

Número total de empregados na usina

\begin{tabular}{lccccc}
\hline \multirow{2}{*}{ Emprêsas } & \multicolumn{5}{c}{ Ano } \\
\cline { 2 - 6 } A & 1960 & 1961 & 1962 & 1963 & 1964 \\
\hline B & 37,0 & 35,8 & 38,4 & 39,9 & 38,9 \\
\hline C & 45,4 & 38,4 & 39,4 & 41,7 & 45,6 \\
\hline D & 18,7 & 17,0 & 16,4 & 15,9 & 19,1 \\
\hline E & - & 30,2 & - & - & 42,9 \\
\hline F & - & 13,8 & 13,9 & 13,6 & 16,9 \\
\hline G & 41,4 & 32,2 & 35,5 & 39,9 & 45,2 \\
\hline H & 52,8 & 54,6 & 51,3 & 51,2 & 54,5 \\
\hline
\end{tabular}

Abril/Junho 1969 
ANEXO II:

Indices Integrados de Produtividade de Mão-de-Obra em NCr $\$ 1.000$

Total de faturamento

$=\overline{\text { Número total de empregados na emprésa }}$

\begin{tabular}{|c|c|c|c|c|c|c|}
\hline \multirow[b]{2}{*}{ Emprêsas } & & \multicolumn{5}{|c|}{ Ano } \\
\hline & & 1960 & 1961 & 1962 & 1963 & 1964 \\
\hline \multirow{2}{*}{ A } & Valor absoluto & 933 & 955 & 1.616 & 3.240 & 4.617 \\
\hline & Número Indice & 100 & 102,3 & 173,2 & 347,2 & 494,8 \\
\hline $\mathrm{B}$ & & - & - & - & - & - \\
\hline \multirow{2}{*}{ C } & Valor absoluto & 468 & 615 & 930 & 2.125 & 3.103 \\
\hline & Número Índice & 100 & 131,4 & 198,7 & 454,0 & 663,0 \\
\hline \multirow{2}{*}{ D } & Valor absoluto & 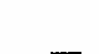 & 1.188 & 1.502 & & 5.550 \\
\hline & Número Indice & & & & & \\
\hline \multirow{2}{*}{$\mathrm{E}$} & Valor absoluto & 467 & 592 & 933 & 1.668 & 3.763 \\
\hline & Número Indice & 100 & 126,7 & 199,7 & 357,1 & 805,7 \\
\hline \multirow{2}{*}{ F } & Valor absoluto & 1.331 & 1.459 & 2.037 & 4.062 & 7.768 \\
\hline & Número Indice & 100 & 109,6 & 153,0 & 305,1 & 583,6 \\
\hline \multirow{2}{*}{ G } & Valor absoluto & 1.106 & 1.427 & 2.054 & 4.015 & 6.990 \\
\hline & Número Ind: $\approx e$ & 100 & 129,0 & 185,7 & 363,0 & 632,0 \\
\hline \multirow{2}{*}{$\mathrm{H}$} & Valor absoluto & 2.428 & 2.627 & 3.942 & 7.717 & 12.520 \\
\hline & Número Indice & 100 & 108,1 & 162,3 & 317,8 & 515,6 \\
\hline
\end{tabular}

BIBLIOGRAFIA

CEPAL. Estudio de la Economía Siderúrgica de América Latina.

Anuário Banas, Siderurgia, São Paulo, 1960-65, 1962, 1966.

United States Departament of Labor. Indexes of Output per Man Hour, Steel Industry, 1957-1963.

Instituto Latinoamericano del Fierro y del Acero, Reuniōes Técnicas do ILAFA em Lima, 1965.

Harbison, F. e Myeris, Ch. A. Educação, Mão-de-Obra e Crescimento Econômico, Fundo de Cultura, Rio de Janeiro, 1965. 